\title{
Classification Modelling for the Impact of Historical Site on Residential Property Rental Value in Osogbo, Nigeria
}

\author{
Oyedeji, Joseph Oyewale \\ Estate Management Department, The Bells University Of Technology, Ota, Nigeria \\ *Corresponding author: diranjosh@yahoo.com
}

\begin{abstract}
Previous studies have revealed that historical sites have impact on property value. However, none of the previous studies have forecasted the impact of historical site on residential property value using a classification model. Data for the study were gathered from the record of recent letting in the study area. For the purpose of precision, this study adopted artificial neural network, logistic regression and support vector machine as model of classifying the rental value of residential property in Osogbo, Nigeria. The study considered relevant variables which include distance to cultural site, age of building, state of exterior and state of interior as input variables. Findings from the study revealed that the three adopted forecasting models have over $80 \%$ percent of the forecasted properties correctly classified which make the property forecasting reliable.
\end{abstract}

Keywords: classification, forecasting, historical sites

\subsection{INTRODUCTION}

Historical and cultural sites influence values of real estate properties that are located within their proximity. It has been said that prices of properties play a vital role in determining the volume of new investments in construction projects (Zheng et al., 2012). Other investigations have proven that preservation of cultural and historic sites enhance residents' and visitors' perception of a neighbourhood (Zahirovic-Herbert and Chatterjee, 2012) and promote urban economic development (Slaughter, 1997, Samimi et.al., 2011). Based on the foregoing, it is evident that close proximity to locations of historic/cultural site affects the values that are attached to properties.

There is a considerable literature on the understanding of the impact of historical/cultural site on property values. The study by Leichenko et.al. (2001)that measures the impact of historic sites on the residential property value in a neighbourhood in Texas is an illustrative example. On the other hand, contradictory findings about the impact of historical site on property values have also emerged from past studies. The study by Zahirovic-Herbert et al (2012) had reported that designation of a site as a historical location has a positive impact on property value. In contrast, Schaeffer and Millerick (1991) discovered that historic designation have a neutral effect on property value. This divergence of the results might be linked to the changes in property investors' behaviour/attitude. In addition, the impact of historical location may also be country/study area specific. Therefore, this present study sets out to develop predictive models that can be used to predict rental values of residential properties that are located within close proximity to historical sites in Nigeria.

This study is justified by absence of similar studies in Nigeria. In addition, previous studies have focused on impact of local and national historical designations on property values but none of the studies have considered the impact of international historic designation on the property values. Furthermore, majority of previous studies did not considered historic designations used for religious purpose. In this study, a predictive model will be developed to predict rental values of residential properties close to a UNESCO listed site "Osun-Osogbo groove". Osun-Osogbo groove is an historic 
religious site listed by the United Nations Educational Scientific and Cultural Organization (UNESCO). The impact of the groove will be predicted on four neighbourhoods in the city at an interval of $200 \mathrm{~m}$ to a distance of $800 \mathrm{~m}$ from the site.

\subsection{LITERATURE REVIEW}

\subsection{Study Area}

The selected study area is located at Osogbo, Osun State, Nigeria. Osun-Osogbo sacred groove holds historical significance in the Yoruba culture. The recognition of this significance led to the recognition and listing of Osun scared groove as a United Nations Educational, Scientific and Cultural Organization (UNESCO) world heritage site in 2005 (World Heritage Scanned Nomination, 2005).There is an annual festival that attracts tourist from all over the world to commemorate and celebrate the history attached to the location. Further details about the event can be found from the Nigeria Tourism Development Commission website .Osogbo is also the administrative capital of Osun state. The land size of the state is 3572 square miles and Osogbo measures approximately 18.15 square miles (Jiboye, 2004). The number of people living within the state was 3,423,535 in 2006 (Nigerian Population Census, 2006).

\subsection{Studies on the impact cultural sites on property value}

The understanding the impact of cultural sites avail potential real estate investors with information about effect of historical designations on their potential investments and the nature of influence that historical designation could have on their investment as established by Coulson and Leichenko (2001). In addition, the knowledge of impact of historical designations on property value will help asset managers and real estate brokers to make informed buy or sell decisions on properties as pointed out by Zahirovic-Hebert and Gibler (2012).

Different nomenclatures had been used to describe impact of cultural sites on property value. Some scholars referred to the topic as listed buildings and sites, historical sites and buildings and cultural sites. All the various nomenclatures are referring to impact of ancestral sites on property value. Previous studies revealed that cultural sites have contradicting impacts on property value depending on the location and uniqueness of the cultural sites. In some clime, historical sites are believed to negatively impact property value because of preservation ordinance requirements. Kattari (2005) asserted that when a property is in a historic district, the costs associated with its maintenance are assumed to increase due to maintenance requirement of the preservation ordinance for the district. The study further posited that the increase in cost of maintenances will consequently reduce the economic value and trading price of the property. However, this assertion can only hold in a clime where there is an enforceable preservation law for historical sites and neighbourhoods. In a country with no enforceable preservation law for historical sites, the assertion may not hold.

\subsection{Factors associated to property values}

Different property attributes have been identified to have an impact on property value. Abidoye and Chan (2016) categorized property attributes into three groups namely, structural, neighbourhood and location. It has been revealed that structural attributes have the most impact on the value of residential properties. It was found by Abidoye\& Chan (2017) that number of servant's quarters has the most significant impact on the sales values of residential properties in Lagos. In contrast, Lam et al. (2009 ) reported that garden has significant impact on value of residential properties in Hong Kong. This variance shows that the factors influencing property value tend to be market specific. Other structural attributes affecting the value of residential properties include: number of bedrooms; number of toilets; number of bathrooms; property type; number of boy's quarters; number of parking space; age of property and number of floors (Abidoye\& Chan, 2017; Lam et al., 
2009; Nghiep\& Al, 2001). Holistic understanding of the factors influencing the value of residential properties would ensure investors get optimal returns from investments.

In previous researches, neighbourhood attributes have been used to predict the value of residential properties. Ajibola, et.al. (2011) examined the impact of gated neighbourhoods on residential property values in Lagos. The study compared rental value of two close neighbourhoods where one is a gated neighbourhood and the other is a non-gated one. Findings from the study revealed that property value in the gated community is higher than that of non-gated community. Olajide and Lizam (2016) assessed the impact of residential neighbourhood crime on residential property value. Findings from the study revealed that neighbourhood crime have a negative impact on residential property value. Popoola et. al. (2015) examined the effect of environmental quality on property rental value in Minna, Nigeria. The study revealed that environmental quality does not have effect on rent. However, Rosiers, et. al (2002) examined the impact of different landscaping attributes on property value. The study revealed that trees only enhanced property value in areas dominated by retired citizens. In addition, landscaping features which include lawn cover, flower arrangements, rock plants and the presence of hedge have a positive impact on residential property value.

A number of previous researches have evaluated the impact of locational attributes on property value. It was revealed in a study in New Zealand that proximity to high voltage transmission lines has no impact on the value of residential properties (Bond \& Hopkins, 2000). In addition, it was noted by Espey and Lopez (2000) that airport noise has a negative impact on property value. Crompton (2001) also examined the impact of proximity to recreation parks on residential property rental value in United State of America. Findings from the study revealed that the rental value of residential property close to recreation sites increased by 20 percent. The study posited further that the increase in rental value would reduce the payback period for developing the recreation parks. Nwosu and Olofa (2015)examined the impact of proximity to waste dump site on residential property value in Ibadan Nigeria. The findings from the study revealed that proximity to the waste dump site has no impact on residential property value in the study area. It was further revealed that there are other locational attributes that have impact on residential property value and the attributes comprise proximity to university, proximity to the market and transport infrastructure (Mathews, 2006; Bello and Adebisi, 2014; Mulley et al., 2016).

\subsection{Models Used In Examining the Impact of Cultural Site on Property Value}

In earliest study on impact of historic sites on property value, difference-in-difference approach was adopted. The property values within a designated district are compared to those in nondesignated areas through the use of this approach. It was adopted by Scribner (1976) who conducted a study on the local district of Baltimore, Maryland and concluded that properties in historic districts have higher prices than other similar properties not located in historic districts. In addition, Rackham (1989) conducted a study on two Chicago suburbs of Elgin and Aurora. Aurora was established as a historic district in 1984 and Elgin was established as a historic district in 1985. Coffin (1989) found that historic designation increased property values in Aurora, but it was not statistically significant in Elgin. However, the major shortfall of this method is that it only considers changes in the average prices of the properties evaluated. It doesn't consider other factors that could influence the price of the house, such as neighbourhood or property characteristics.

In order to overcome this shortcoming, most recent studies have adopted multiple-regression models that consider all associated factors that could influence property value. Leichenko, et.al. (2001) examined the impact of historic preservation on residential property values in the City of Texas by adopting hedonic pricing model. The study tried to fill the gap of previous research that focused on examination of an impact of one historic site on a neighbourhood and this tend to make many to believe that the impact of historic sites is mostly positive on residential properties. The study considered many historical sites and their impacts on different neighbourhoods. The study discovered that historic designation is associated with higher property values. There are also other studies that 
revealed that five (5) historic properties and properties located within an historic district sell for a premium (Ford, 1989; Coffin, 1989). There are also studies that revealed the negative impact of cultural sites on property values. In a study conducted by Nwosu and Huffman (1994) on the impact of historic sites on residential property value in Philadelphia, it was discovered that historic sites negatively affect the value of residential properties in the neighbourhood. The study adopted hedonic pricing model. It was also discovered by Schaeffer \&Millerick (1991) and Leichenko et al (2001) of the neutral effect of cultural sites in Chicago on property values. The study adopted a difference-indifference approach to access the impact of historic designation on property values in the city of Chicago.

Furthermore, there are other studies that adopted different types of multivariate models. The multivariate models were adopted to be an improvement on the difference-in-difference approach that was used by earlier studies. However, it is important to emphasise that the impact of historic sites on property values cannot be generalised but predicted on an individual basis (Leichenko et al., 2001). Zahirovic-Herbert $\mathrm{V}$ et al (2012) adopted quantile regression analysis to evaluate the impact of historic designation on residential property value in Baton Rouge, Louisiana, USA. The study discovered that historic designation have a positive impact on residential property value in Louisiana. Noonan (2007) also adopted hedonic pricing model to study the impact of historic designation on property price in Chicago. The study discovered that historic designation have a positive impact on property value in Chicago.

Past studies have revealed the importance of some factors in the study of impact of cultural sites on property value. Listokin (1999) established that property values increases or decreases attributed to local designation should be individually considered. The study also established that fluctuations in property value can be attributed to a broader set of real estate market forces rather than a single historic site. The study that focused on residential property values identified real estate market forces that determines property value which include location, level of public investment, access to public transport and other amenities. In addition, Schaeffer and Millerick (1991) in Leichenko et al (2001) posited that the impact of historic sites on residential property value depends on whether the historic designation is local or national. The study discovered that national historic sites have a positive impact on property value and local historic sites have a negative impact on property value. The major limitation of the study has to do with the methodology which is difference-in-difference approach which doesn't put into consideration other factors that could affect property value apart from presence of historic sites. The study did not put into consideration impacts of international historical sites.

In another elaborate study conducted by Gilderbloom et.al. (2009), the impact of historic designation was measured on property values, job creation and environmental sustainability. The study adopted a job simulation multiplier model to study effect of historic designation on job creation and a regression analysis model to study effect of historic designation on property value. The study discovered that there is an increase in job creation in designated areas. Property value also increased in designated areas while stagnant in non-designated areas. In addition, it was discovered that sustainability attitude of residents of designated areas is higher than those in non-designated areas.

The need for accuracy and predictive ability of study models of house pricing has generated some innovations in the study of house pricing. Lazrak et.al. (2014) had adopted a spatial hedonic model which is an application of geographical information system software. The study provided one of the first applications using a spatial auto-regressive model to investigate the impact of cultural heritage of listed buildings and cultural heritage sites. The study that was conducted in Berlin was possible because of availability of a vast database for the property market. This study has introduced innovation to the study of historical designation and property value through the adoption of artificial neural network and other artificial intelligence to evaluate the impact of historical designation on property value in the study area. Nguyen and Cripps (2001) had conducted a study of historic designations and property value through the comparison of artificial neural network and multiple 
regression analysis. It was discovered that artificial neural network has the ability to forecast the nature of the relationship between historic designation and property value.

Franco and Macdonald (2018) had examined the effect of cultural heritage on residential property values in Lisbon Portugal with protected historic landscape. The study considered local urban amenities as variables and the analysis was done using hedonic estimations with a mixed geographically weighted regression. The analysis further employed a geographic regression discontinuity to test the robustness of results. It was gathered that built cultural heritage is shown to have very localised positive impacts on nearby dwelling prices. The effects of the heritage assets however are highly dependent on type and relative neighbourhood context.

In conclusion, the impact of cultural site on property value is a relative concept. The impact could be positive, negative or neutral depending on some other important factors that affect the property market and properties in a certain location. Some of these factors are location, accommodation details of the property, age of buildings and accessibility. This justifies the need for a multiple regression model that will consider all the necessary factors that might influence property value in a study area.

\subsection{METHODOLOGY}

To date, several research methods have been adopted in built environment related studies. A review of built environment studies reveals that multiplicity of research methods can be found in literature (Laryea and Leiringer, 2012). The research methods found in literature include survey, experiment, literature survey, case-study, modelling, archival research and grounded theory (Laryea and Leiringer, 2012). Wing et al. (1998) affirms that the choice of research method(s) largely depends on the problem addressed by the study. The use of modelling approaches is particularly useful in predicting rental price ( $\mathrm{Li}$ and $\mathrm{Li}, 1996)$. Furthermore, Fellow and Liu (2015) have asserted that modelling research method is adequate for investigating relationship and predicting outcomes. Based on the foregoing, modelling techniques are utilised in the present study since the main objective of the present study is to predict property rental value. In addition, the predictive accuracy (i.e. generalisation) of the developed model is to be reported.

\subsection{Modelling}

Artificial intelligence (AI) models were applied in this study to forecast rental values of property. The main reason for adopting AI models is due to its predictive accuracy when compared with conventional (i.e. regression) models (see Goh, 1996; Lam et al., 2009). Support vector machine (SVM) was also adopted in this study is due to its relative accuracy in property value prediction (Lam et al. 2009). Traditionally, linear regression model are utilised in investigating the predicting dependent variable based on a set of independent variables (i.e. classification problems). Hence the results of the SVM were compared with those of multiple ordinal logistic regression (MOLR). AI models have become popular for application in property valuation research (Nguyen and Cripps, 2001; Lam et al., 2009; Selim, 2009). The variable to be included in an AI model are rarely known beforehand. The variables included in the models are similar to those found in extant literatures (see Table 1). In addition, in order to evaluate the influence of 'closeness to tourist site' on property value, this variable was included in the developed model. The processes of development of the two models are explained in the 'model development' subsection. Measures of accuracy were used to evaluate and compare the predictive power AI and conventional models. The dataset used in model development were collected from Oshogbo, Osun-state, Nigeria. 


\subsection{Modelling Development Process}

The first stage of the study involved identification of a list of property attributes often associated theoretically with property rental values. The first stage was carried out using a review of past literature. Data on two hundred (200) recently completed transactions were collected from property owners. This is because the property rental market in Osogbo, Osun state is largely dominated by the informal sector. The collected data were pre-processed and stored in a computer for further analysis.

Data on property attributes were used as an input variables and rental property price as the output variable. At the second stage, the collected data is divided into two: training set $70 \%$ and test set $30 \%$. The training data set were initially fitted to the model. Subsequently, the trained model is used to predict previously unseen data i.e., test data set. This was done to validate the developed models and evaluate its predictive accuracy (generalisation capability). The percentage of correctly classified cases and Cohen's kappa coefficient (Kappa) are computed as measures of predictive performance. In addition, sensitivity analysis as proposed in Cortez (2010) was utilised in assessing the relative importance of the input variable in the developed model.

\subsection{The input variable used in the models}

The property attributes that influence the rental value of residential real estate properties have been identified in several studies ( $\mathrm{Li}$ and $\mathrm{Li}, 1996$, Lam, Yu and Lam, 2008). Previous studies have demonstrated that the determinants of residential property values vary from one country to another $(\mathrm{Li}$ and Kabba., 2011). It is reasonable to suggest that determinant of property values are unique and location specific. The determinants of rental value of residential properties comprise of the following: 1) DFCS - Distance From Cultural Site, 2) House Types, 3) Age of Building, 4) State of exterior, 5) State of interior , 6) Availability of water , 7) Road Network, 8) Availability of neighbourhood security, 9) Rent P.A. The listed indicators (i.e. property attributes) are used for the purpose of this study. The models developed earlier are utilised to capture the relationship between these indicators and rental property values (output).

\subsection{The output of the model}

The output variable in the models which are reported in the this study is the rental value of residential property. The rental value of the residential properties have been classified into four (4) groups (namely group A - less than 50,000 Naira per annum; group B - between 51,000-100,000 Naira per annum; group C - between 101,000-200,000 Naira per annum; and group D -between 201,000300,000 Naira per annum).

\subsection{RESULTS AND DISCUSSION}

The reference point for data gathering is Osun Osogbo groove. The groove was adopted because the second phase of this study is to conduct sensitivity analysis of the impact of the identified parameters on residential property pricing in Osogbo and to measure the impact of the groove on residential property value adopting the same models. 


\subsection{Classification Model}

\section{Parameters}

Table 1: The pre-processed input and output variables

\begin{tabular}{|c|c|}
\hline Attribute & Description (Domain) \\
\hline DFCS & Distance from cultural site \\
\hline House types & Type of accommodation \\
\hline Age of Building & Year of construction \\
\hline State of exterior & Level of exterior finishing \\
\hline State of interior & Level of interior finishing \\
\hline Availability of water & Source of water supply \\
\hline Road network & Road accessibility to building \\
\hline Neighbourhood security & Safety of neighbourhood \\
\hline Rent P.A. & Annual rent \\
\hline
\end{tabular}

\subsection{Classification}

\section{Artificial Neural Network}

Correctly classified $148-89.70 \%$

Incorrectly classified $17-10.30 \%$

RMSE $=0.1875$

\section{SUPPORT VECTOR MACHINE (SVM 1)}

$\mathrm{C}=1$

Correctly classified $144-87.27 \%$

Incorrectly classified $21-12.73 \%$

RMSE $=0.3284$

\section{SUPPORT VECTOR MACHINE (SVM 2)}

$\mathrm{C}=2$

Correctly classified $148-89.70 \%$

Incorrectly classified $17-10.30 \%$

$\mathrm{RMSE}=0.3253$

Root Mean Square Error - Actual - Forecasted 


\section{LOGISTIC REGRESSION}

Correctly classified $142-86.06 \%$

Incorrectly classified $23-13.94 \%$

$\mathrm{RMSE}=0.2112$

\section{Discussion}

The classification of the models shows that the three adopted models have over $80 \%$ of their data correctly classified. $89.70 \%$ of the Artificial Neural Network analysed data were correctly classified and $10.30 \%$ incorrectly classified, which translates into 148 correctly classified data and 17 incorrectly classified data. In addition, Support Vector Machine with a Slack variable $\mathrm{C}=1$ has $87.27 \%$ of the analysed data correctly classified and $12.73 \%$ incorrectly classified, this translates into 144 correctly classified data and 21 incorrectly classified data. Furthermore, Support Vector Machine with a Slack variable $\mathrm{C}=2$ has $89.70 \%$ of the analysed data correctly classified and $10.30 \%$ incorrectly classified, this translates into 148 correctly classified data and 17 incorrectly classified data. Finally, the Logistic Regression has $86.06 \%$ correctly classified data and $13.94 \%$ incorrectly classified data, this translates into 142 correctly classified data and 23 incorrectly classified data.

The Root Mean Square Error (RMSE) which is the level of error in the classification of each of the models is minimal. The RMSE of the Artificial Neural Network model is 0.1875 which can be translated as $18.75 \%$ and the RMSE of Support Vector Machine with Slack variable C $=1$ is 0.3284 which translates into $32.84 \%$. The RMSE of Support Vector Machine with Slack Variable C= 2 is 0.3253 which translates into 32.53\%. and RMSE of Logistic Regression is 0.2112 which translates into $21.12 \%$. It can be inferred that the level of data that are correctly classified based on the adopted models are high. The errors associated with classifications are relatively low except the RMSE of the Support Vector Machine that is above 30\%. Therefore, the classifications can be adopted for predicting residential rental property value in the study area. ANN has the highest predictive capability due to $89.70 \%$ of its data correctly classified and the lowest RMSE of 0.1875 .

\section{CONFUSION MATRIX ANN}

$$
\begin{array}{ccccc}
\mathrm{a} & \mathrm{b} & \mathrm{c} & \mathrm{d} & \\
57 & 4 & 0 & 0 & \mathrm{a} \\
2 & 52 & 1 & 0 & \mathrm{~b} \\
0 & 2 & 28 & 3 & \mathrm{c} \\
0 & 0 & 5 & 11 & \mathrm{~d}
\end{array}
$$

The rental value classifications in the study area are: N0 - N50,000 p.a, N51,000 N100,000p.a, N101,000 - N200,000 p.a , and N201,000 - 300,000p.a . Based on the ANN classifications, 61 houses falls within the N0 - N50, 000 rental value range, out of these 61 houses, 57 houses rental value are correctly classified, and 4 houses rental value are incorrectly classified. In addition, 55 houses falls within the N51,000 - N100,000 rental value class, out of which 52 houses are correctly classified and 3 houses are incorrectly classified. Furthermore, 33 houses falls within the rental price range of N101,000 and N200,000, out of which 5 houses are incorrectly classified and 28 are correctly classified in terms of rental value. Finally, 16 houses are categorized in the N201, $000-$ $\mathrm{N} 300,000$ rental value ranges, out of which 5 houses are incorrectly classified and 11 houses are correctly classified. It can be inferred, that based on the property attributes considered, the incorrectly 
classified houses have their rental value either overvalue or undervalue by the landlord of the houses, while the correctly classified houses have their rental value rightly categorized based on the property attributes.

In addition, it can be deduced that 57 correctly classified houses out of 61 houses in "a" are with the lowest rental value that ranges between $\# 0$ - \#50,000. Furthermore, 52 correctly classified houses out of 55 houses in "b" have a rental value of \#51,000 - \#100,000. In the same light, 28 correctly classified houses out of 33 houses in "c" have a rental value that ranges between \#101,000 \#200,000. Lastly, 11 correctly classified houses out of 16 houses in "d" have a rental value that ranges between \#201,000 - \#300,000. It can be deduced that the highest number of correctly classified houses falls within the lowest rental value and as the rental value increases, the number of houses in different rent categories reduces. It can be concluded that the historic site has a negative impact on the rental value.

$$
\begin{array}{llllll}
\text { SVM } & 1 & \multicolumn{1}{c}{C=1} \\
\text { a } & b & c & d & \\
55 & 6 & 0 & 0 & a \\
4 & 51 & 0 & 0 & b \\
0 & 2 & 26 & 5 & c \\
0 & 0 & 4 & 12 & d
\end{array}
$$

Based on SVM1 with Slacked variable $\mathrm{C}=1,61$ houses have their rental values falls within the range N0 - N50,000, out of these 61 houses, 55 houses are correctly classified and 6 houses are incorrectly classified. In addition, 55 houses were categorised within the N51,000 - N100,000 rental price range, out of which 51 houses have their rental value correctly classified and 4 houses have their rental value incorrectly classified. Furthermore, within the N101,000 - N200,000 rental value range, 26 houses have their rents correctly classified, and 7 houses have their rents incorrectly classified. Finally, 16 houses falls within the N201,000 - N300,000 rental value range with 12 houses correctly classified and 4 houses incorrectly classified.

It can be deduced that 55 correctly classified houses out of 61 houses in "a" are with the lowest rental value that ranges between \#0 - \#50,000. In addition, 51 correctly classified houses out of 55 houses in " $b$ " have a rental value of \#51,000 - \#100,000. In the same light, 26 correctly classified houses out of 33 houses in "c" have a rental value that ranges between \#101,000 - \#200,000. Lastly, 12 correctly classified houses out of 16 houses in " $d$ " have a rental value that ranges between \#201,000 \#300,000. It can be deduced that the highest number of correctly classified houses falls within the lowest rental value and as the rental value increases, the number of houses in different rent categories reduces. It can be concluded that the historic site has a negative impact on the rental value.

$\begin{array}{llllll}\text { SVM } 2 & & \mathrm{C}=2 & \\ \mathrm{a} & \mathrm{b} & \mathrm{c} & \mathrm{d} & \\ 57 & 4 & 0 & 0 & \mathrm{a} \\ 4 & 51 & 0 & 0 & \mathrm{~b} \\ 0 & 2 & 27 & 4 & \mathrm{c} \\ 0 & 0 & 3 & 13 & \mathrm{~d}\end{array}$


From the SVM2 with Slacked variable $=2,61$ houses falls within N0 - N50,000 rental value range, out of which 57 houses are correctly classified and 4 houses are incorrectly classified. In addition, 55 houses were classified in the N51,000 - N100,000 rental value range and 51 houses are correctly classified and 4 houses are incorrectly classified. Furthermore, 33 houses falls within the N101,000 - N200, 000 rental value range, out of which 6 houses have their rental values incorrectly classified. Finally, 16 houses were classified within the N201,000 - N300,000 rental value range. 3 houses out of the 16 are incorrectly classified and 13 houses are correctly classified.

In addition, it can be deduced that 57 correctly classified houses out of 61 houses in "a" are with the lowest rental value that ranges between $\# 0$ - \#50,000. Furthermore, 51 correctly classified houses out of 55 houses in "b" have a rental value of \#51,000 - \#100,000. In addition, 27 correctly classified houses out of 33 houses in "c" have a rental value that ranges between $\# 101,000$ - \#200,000. Lastly, 13 correctly classified houses out of 16 houses in "d" have a rental value that ranges between \#201,000 - \#300,000. It can be deduced that the highest number of correctly classified houses falls within the lowest rental value and as the rental value increases, the number of houses in different rent categories reduces. It can be concluded that the historic site has a negative impact on the rental value.

\section{LOGISTIC REGRESSION}

$\begin{array}{lllll}\mathrm{a} & \mathrm{b} & \mathrm{c} & \mathrm{d} & \\ 57 & 4 & 0 & 0 & \mathrm{a} \\ 6 & 46 & 3 & 0 & \mathrm{~b} \\ 0 & 1 & 27 & 5 & \mathrm{c} \\ 0 & 0 & 4 & 12 & \mathrm{~d}\end{array}$

From the logistic regression, 61 houses fall within the N0 - N51,000 rental value, 57 houses out of these 61 are correctly classified and 4 houses are incorrectly classified. It is also noted that 49 houses falls within the N51,000 - N100,000 price range, 46 houses out the 49 are correctly classified and 3 houses are incorrectly classified. Furthermore, 33 houses falls within rental price range of N101,000 - 200,000, 27 houses out of these 33 are correctly classified, and 6 houses are incorrectly classified. Finally, 16 houses falls within the price range of N201,000 - N300,000, 4 houses out of the 16 are incorrectly classified and 12 houses are correctly classified.

In addition, it can be deduced that 57 correctly classified houses out of 61 houses in "a" are with the lowest rental value that ranges between $\# 0$ - \#50,000. It is also noted that 46 correctly classified houses out of 55 houses in "b" have a rental value of \#51,000 - \#100,000. In the same light, 27 correctly classified houses out of 33 houses in "c" have a rental value that ranges between $\# 101,000$ - \#200,000. Lastly, 12 correctly classified houses out of 16 houses in "d" have a rental value that ranges between \#201,000 - \#300,000. It can be deduced that the highest number of correctly classified houses falls within the lowest rental value and as the rental value increases, the number of houses in different rent categories reduces. It can be concluded that the historic site has a negative impact on the rental value.

\subsection{CONCLUSION}

In the phase of uncertainty that is characterising property price forecast, it becomes imperative to adopt different advanced forecasting tools to predict property rental value. This necessitates the adoption of three models for the forecast of rental value in the city of Osogbo. The models were adopted for classifying the rental value of properties based on the independent variables considered. It was discovered that a larger percentage of the considered variables were correctly classified adopting the three models. The rate of the correctly classified properties in the study area makes the 
classification models adopted to be reliable. Furthermore, the confusion matrix showed the distribution of the properties according to rental value distributions. The confusion matrixes also revealed the number of correctly classified and incorrectly classified properties in each property price category. It can be deduced that the number of houses in each rental value categories reduces as the rental value increases, which implies that the cultural site has a negative impact on the rental value in the study area. This study is the first part of a study that intends to forecast rental value in the study area. In the second part of this study rental values will be forecasted and not classified as conducted in this study.

\subsection{REFERENCES}

1. R. B., \& Chan, A. P. C. (2016). Critical determinants of residential property value: professionals' perspective. Journal of facilities management, 14(3), 283-300.

2. Abidoye, R. B., \& Chan, A. P. C. (2017).Modeling property values in Nigeria using artificial neural network. Journal of Property Research, 1-18.

3. Ajibola, M.O., Oloke, O.C., \&Ogungbemi, A.O. (2011) Impact of Gated Communities on Residential Property Values: A Comparison of Onipetesi Estate and its Neighbourhoods in Ikeja, Lagos State, Nigeria. Journal of Sustainable Development, 4(2), 063-071.

4. Asbere P.K and Huffman, F.E (1994a) Historic designation and residential market value, The Appraisal Journal 62, pp 396-401.

5. Asbere P.K, Huffman F.E and Mehdian S (1994) "The Adverse Impact of Local Historic Designation: The Case of Small Apartment Buildings in Philadephia" Journal of Real Estate Finance and Economics, Vol.8, No. 3, pp. 225 - 234.

6. Bello, V.A and Adebisi, O (2014) Impact of the Federal University of Technology, Akure on Residential Property Values in Akure, Nigeria, FIG Congress publication.

7. Bond, S., \& Hopkins, J. (2000). The Impact of Transmission Lines on Residential Property Values: Results of A Case Study in a Suburb of Wellington, NZ. Pacific Rim Property Research Journal, 6(2), 52-60.

8. Coffin, D.A (1989) "The Impact of Historic Districts on Residential Property Value" Eastern Economic Journal, Vol. 15 (3), 221- 228.

9. Crompton, J.L (2001) The Impact of Parks on Property Values: A Review of the Empirical Evidence, Journal of Leisure Research, 33(1), 1-31.

10. Espey, M., \& Lopez, H. (2000).The impact of airport noise and proximity on residential property values. Growth and change, 31(3), 408-419.

11. Fellows, R.F and Liu, A.M.M (2015) Research Methods for Construction. $4^{\text {th }}$ Edition, ISBN:978-1-118-91574-5

12. Ford, D.A (1989) “ The Effect of Historic District Designation on Single- Family Home Prices” Real Estate Economics, Vol. 17, (3), 353-362 
13. Franco, S.F and Macdonald, J.L (2018) The Effect of Cultural Heritage on Residential Property Values: Evidence from Lisbon, Portugal. Regional Science and Urban Economics, Elsevier, doi: 10.1016/j.regsciurbeco.2018.02.001

14. Goh, T.N (1996) Economical Experimentation Via 'Lean Design' Quality and Reliability Engineering International 12, $383-388$

15. Gilderbloom, J.I, Hanka, M.J and Ambrosius J.D (2009) Historic preservation's impact on job creation, property values, and environmental sustainability, Journal of urbanism: International Research on Placemaking and Urban Sustainability. ISSN:1754-9175(Print)

16. Katari P (2005) Preservation and Residential Property Values: The Case of Philadelphia. Published M.Sc thesis by University of Pennsylvania, Scholarly Commons, pp. 25.

17. Jiboye A (2004) The Socio-cultural Responsiveness of Household Size on Housing Quality In Osogbo, Nigeria, Anthropologist 6(3), 169-174

18. Lam, K. C., Yu, C. Y., \& Lam, C. K. (2009). Support vector machine and entropy based decision support system for property valuation. Journal of Property Research, 26(3), 213-233.

19. Lazrak F, Nijkamp P, Rietreld P, Rouwendal J (2014) The Market Value of Cultural Heritage in Urban Areas: An Application of Spatial Hedonic Pricing. Journal of Geographical System, 16: 89-114, Springer.

20. Lam, K.C, Yu, C.Y and Lam, K.Y (2008) An Artificial Neural Network and Entropy Model for Residential Property Price Forecasting in Hong Kong. Journal of Property Research, 25(4) pp 321-342.

21. Lam, K. C., Yu, C. Y., \& Lam, C. K. (2009). Support vector machine and entropy based decision support system for property valuation. Journal of Property Research, 26(3), 213-233.

22. Laryea, S and Leiringer, R (2012) Built Environment Research in West Africa: Current Trends and Future Directions. West Africa Built Environment Research (WABER) Conference Proceedings, 797 - 804

23. Leichenko R.M, Coulson N.E and Listokin D (2001) Historic Preservation and Residential Property Values: An Analysis of Texas Cities. Journal of Urban Studies, Vol. 38, No. 11

24. Li, H., \& Li, V. (1996). Forecasting house rental levels: Analytical rent model versus neural network. Journal of urban planning and development, 122(4), 118-127.

25. Li, J and Kabba, V.T (2011) Determinant of Urban Land Price in Freetown, Sierra Leone. Journal of American Science 7(2), 213 - 223.

26. Listokin D (1999) Historic Preservation at Work for the Texas Economy. Centre for Urban Policy Research at Rutgers University (Austin Texas Historical Commission)

27. Mathews, J.W (2006) The Effect of Proximity to Commercial Uses on Residential Property Prices.Being Unpublished PhD Dissertation Submitted to Georgia State University and Georgia Institute of Technology.

28. Mulley, C., Ma. L., Clifton, G., Yen, B., and Burke., M (2016) Residential property value impacts of proximity to transport infrastructure: An investigation of bus rapid transit and heavy rail network in Brisbane, Austrailia. Journal of Transport Geography, 54(1), $41-52$ 
29. Nguyen, N and Cripps, A (2001) Predicting Housing Value: A Comparison of Multiple Regression Analysis and Artificial Neural Networks," Journal of Real Estate Research, American Real Estate Society, vol. 22(3), pages 313-336.

30. Nigeria National Population Census Record 2006

31. Noonan D.S (2007) Finding an Impact of Preservation Policies: Price Effects of Historic Landmarks on Attached Homes in Chicago 1990-1999. Economic Development Quarterly, 2(1), 17-33.

32. Nwosu, A.E \&Olofa, S.A (2015) Effect of Waste Dumpsites on Proximate Residential Property Values In Ibadan, Oyo State, Nigeria. Ethiopian Journal of Environmental Studies \& Management 8(2), 976-982,ISSN:1998-0507.

33. Olajide, S.E \&Lizam, M (2016) Determining the Impact of Residential Neighborhood Crime on Housing Investment Using Logistic Regression. International Electronic Scientific Journal 2(12), $9-18$

34. Popoola, N.I, Jinadu, M.A, Liman, H.S \&Abd'Razack, N.T.A (2015) Effectof Environmental Quality on Rental Values in Peri-urban Neighborhoods of Minna, Nigeria. ATBU Journal of Environmental Technology, 8(2), 42 - 52.

35. Rackam, J.B (1977) Values of Residential Properties in Urban Historic Districts: Georgetown, Washington, DC and other Selected Districts. Washington DC: Preservation Press.

36. Rosier, F.D, Theriault, M , Kestens, Y \& Villeneuve, P (2002) Landscaping and House Values: An Empirical Investigation. Journal of Real Estate Research, 23 (1), 139-

37. Samimi, A, Sadeghi S and Sadeghi S(2011) Tourism and Economic Growth in Developing Countries- P-VAR Approach, Middle East Journal of Scientific Research 10(1): pp 28-32, ISSN 1990- 9233 c IDOSI Publications.

38. Selim, H (2009) Determinants of house prices in Turkey: Hedonic regression versus artificial neural network, Expert systems with Applications 36, 2843 - 2852

39. Schaeffer, A and Millerick, D(1991) The Impact of historic district designation on property values: an empirical study, Economic Development Quarterly, 5, pp. 301-331

40. Scribner, D (1976) Historic districts as an economic asset to cities, The Real Estate Appraiser, May- June, pp 7-12.

41. Slaughter, H. B, Jr (1997) Integrating Economic Development and Historic Preservation in Pittsburgh Pennysylvania, Historic Preservation Forum 11, 41 - 44

42. UNESCO World Heritage Scanned Nomination, 2005

43. Wing, C.K, Raftery, J and Walker, A (1998) The Baby and the Bathwater: Research Methods in Construction Management. Construction Management and Economics16(1), 99-104

44. Zheng, X., Chau, K. W., \&Hui, E. C. M. (2012).The impact of property price on construction output. Construction Management and Economics, 30(12), 1025-1037. 
45. Zahirovic-Herbert V and Gilber K.M (2012) Historic District Influence on House Price and Marketing Duration. Journal of Real Estate Finance Economics 48:112:13, DOI 10:1007/s1114601293801

46. Zahirovic-Herbert V and Chatterjee S (2012) Historic Preservation and Residential Property Values: Evidence from Quantile Regression. Urban Studies, 49(2),369-382 